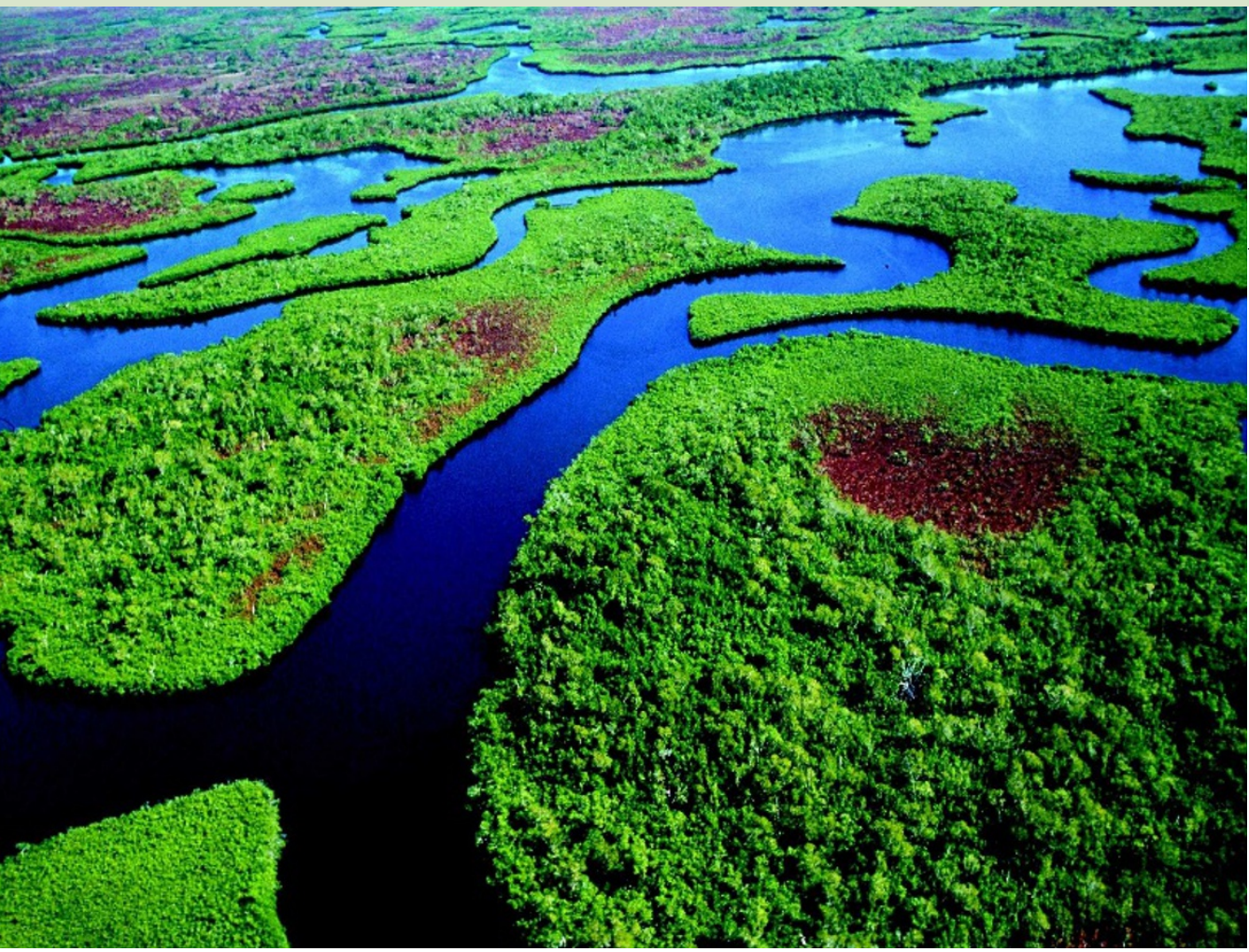

Studies of Florida's mangrove islands have helped researchers to understand how biodiversity develops.

earlier. It states that the number of species on an island depends on the rates of immigration and extinction, which are influenced by the distance of an island from the mainland and the island's size. Notably, the number does not depend on what the species are, nor on the roles they have in their ecosystems, known as niches.

Evolutionary biologist and science writer Menno Schilthuizen retells the story of the Wilson-Simberloff experiment at some length in The Loom of Life. His book is a readable, anecdotal introduction to the ecology of diversity, addressing basic questions about why there are so many different species and why some species are rare and others common.

Yet the book is hard to get into. It lacks a straightforward introduction and, with uninformative chapter titles such as 'The more the merrier', a reader who idly picks it up would need to read 50 pages to understand where all the stories are going. It is not until this point in the book - after touring through the scientific usefulness of isolated ecosystems, the history of the idea of food chains, the staggering amount of global biodiversity, and the idea that each species inhabits a slightly different niche - that the first hints of dispute enter the plot.

Schilthuizen sets out the idea that two species can coexist in the same ecosystem only if they have different niches. Evolutionary theory predicts that two species with the same living requirements and appetites would go head-tohead, and if one is even infinitesimally more efficient at exploiting their shared niche, it will, over the course of generations, outcompete and exterminate the other. Then he drops the bombshell. What about phytoplankton? Any one patch of water contains hundreds of different species, all swimming in the same water, all competing for the same energy source: sunlight. Even with the odd difference in mineral uptake, how could so many niches exist in the uniform surface of the sea? Ecologists could go mad trying to find the minute niche differences at work; maybe there is an easier way.

After launching into the history of island biogeography, Schilthuizen introduces Stephen Hubbell's unified neutral theory of biodiversity, which Schilthuizen describes as aiming "to mimic and predict real, broad brush biodiversity patterns while ignoring the

\section{Atmosphere ... The Climate Revealed by Ice Museum of Arts and Crafts, Paris Until 30 April 2009}

With rising levels of emotion clouding the political debate about global climate change, a new exhibition at the Museum of Arts and Crafts (Musée des Arts et Métiers) in Paris provides a timely reminder that accurate data are the basis of scientific objectivity. Running until April next year, Atmosphere shows how the past 50 years of scientific observation in the Arctic and Antarctic have provided evidence of Earth's vulnerability and changed how we view our planet. The exhibition, says geochemist Jean Jouzel, one of its two scientific commissioners, "provides a clarion call to use this carefully collected data to take informed action against climate change". niches that undeniably existed". The theory puts forth a simple predictor of the abundance of various species in an ecosystem using only the rate of migration and a fundamental biodiversity number that takes into account the rate of speciation. In general, the theory shows how abundances of each species drift up and down. Sometimes new species enter the system, occasionally one will go extinct, and now and then one will speciate into two.

It is odd that the book does not give a precise definition of 'neutral' in the neutral theory, namely the assumption that any differences between the behaviour of the various species being considered - all the trees in a forest, say, or all the corals on a reef - have no overall effect in the model.

Clearly a fan of the theory, Schilthuizen makes time for its opponents, even if he uncharitably calls their negative reactions "kneejerks". He sets out the evidence from both sides but avoids hashing it out, jumping on instead to ecosystem stability. All these questions are related, but the book counters expectations by becoming a survey of the great questions about the ecology of diversity instead of an argument in favour of the neutral theory.

The Loom of Life is useful. Much of the public - and even some of the professional environmental movement - knows little about the rules ecologists have posited for creating and maintaining biodiversity. They might read this slender book for a bearing on how to tackle environmental problems.

Emma Marris is a correspondent for Nature based in Columbia, Missouri.

\title{
Paris feels the polar chill
}

The starting point for Atmosphere is the International Geophysical Year of 1957-58. Objects on show in the exhibition include scientific instruments used at the poles, newspaper reports, scientific papers and books, photographs and films. Charcot, the first French polar expedition base in Antarctica, is photographed almost submerged in snow and resembles a surfacing submarine, its tricolour flag taut in the Antarctic wind. Although the focus is on raising awareness of the French contribution to polar research, the work of other nations and international collaborative groups is also presented. Polar wildlife and landscape photographs, including spectacular aurora borealis displays, document the fauna and natural beauty of the polar regions. The 130 exhibited objects range from an apparatus that simulates the aurora borealis 
in the laboratory, to a 'Weasel' tracked vehicle used for transport across the snow and ice.

Jouzel's own research is included - his sampling to a depth of 3,000 metres, of polar ice that was laid down some 500,000 years ago, is crucial to our current understanding of how Earth's atmosphere has changed during this time. By analysing the composition of tiny bubbles of air trapped in polar ice, he established a correlation between temperature and the concentration of greenhouse gases, specifically carbon dioxide and methane, during successive climatic cycles. By revealing what occurred in the past, scientists can understand how best to prevent further damage to the planet. Several conferences will be held during the exhibition to alert the public to the need to change attitudes and behaviours that contribute to global warming. "But Sarah Palin is not welcome," jokes Jouzel, referring to the climate-change scepticism of the Republican vice-presidential nominee in the US election. "She is not invited."

Colin Martin is a writer based in London, UK. e-mail:cmpubrel@aol.com

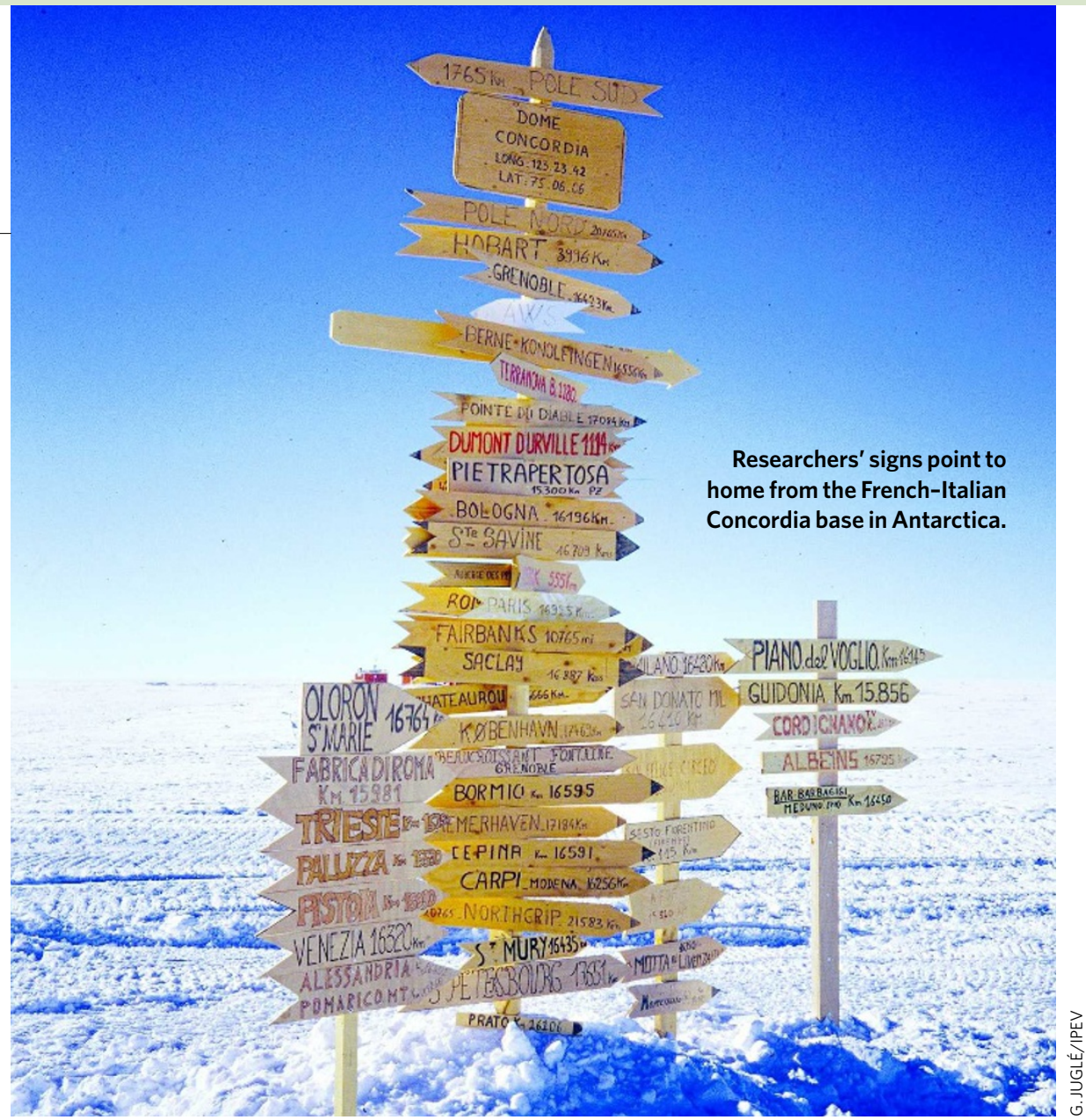

\section{A snapshot of hidden science history}

\section{Brought to Light: Photography and the Invisible, 1840-1900 \\ San Francisco Museum of Modern Art, California \\ Until 4 January 2009}

The use of photography in science during the nineteenth century is traced in a new exhibition at the San Francisco Museum of Modern Art, running until 4 January 2009. Brought to Light showcases scientific photographs that reveal phenomena invisible to the unaided eye, from early X-rays of the body's skeleton to fields of electricity.

Scientists first considered photography as little more than a quicker way of recording the world than drawing, but soon realized that it could be used to gain access to aspects of the world that had previously been off limits. Early photographs of the Moon, the surface of the Sun, and of distant nebulae and their spectra changed astronomers' understanding of our Universe. Popular photographs of microscopic objects, such as crystals and insects, revealed new complexity in the everyday world. Indeed, in 1877, astronomer Pierre Jules César Janssen declared that the photographic plate was the "true retina of the scientist".

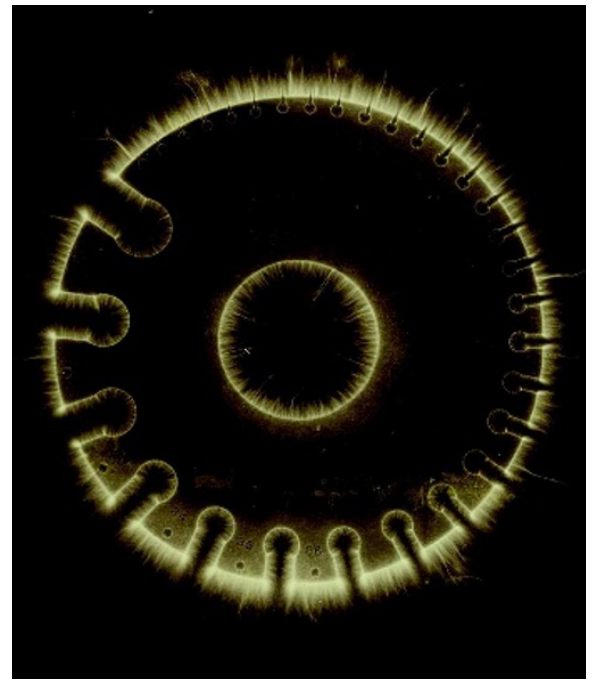

Hermann Schnauss's photo revealed how sparks of electricity emanate from a metal wire gauge.

Photography evolved rapidly with the new sciences. An X-ray image that Wilhelm Conrad Röntgen took of his wife's hand in 1895 , for instance, was widely reproduced by others who were fascinated by the ability to see inside the human body. As exhibit curator Corey Keller writes in the catalogue,
“Today we are hardly shocked by the sight of our own bones, but we can glean from the remarkable public response just how extraordinary these pictures were when they first appeared, simultaneously suggesting an assault on privacy and conjuring the specter of death."

Keller argues that, by showing there was more going on in the world than was apparent to the unaided eye, scientific photographs inspired a fundamental shift away from faith in the human observer to faith in the authority of technology. And by the end of the nineteenth century, the heyday of the 'educated amateur' had ended. Scientists were becoming the specialized practitioners they are today, using powerful, expensive and complicated tools to explore realities that remain invisible to most.

By revealing the hidden forces at work in nature, the pictures collected in this exhibit have much in common with iconic modern images, such as the views of galaxies in the distant Universe captured by the Hubble Space Telescope. In that way, the exhibit does not just illuminate the past - it also gives a glimpse of the future.

Erika Check Hayden is a correspondent for Nature based in San Francisco. 